\title{
Physiological tolerance of marine calanoid copepod eggs to sulphide
}

\author{
P. Nielsen ${ }^{1}$, J. Mortensen ${ }^{1}$, B. Vismann ${ }^{2}$, B. W. Hansen ${ }^{1, *}$ \\ ${ }^{1}$ Roskilde University, Department of Life Sciences and Chemistry, PO Box 260, 4000 Roskilde, Denmark \\ ${ }^{2}$ University of Copenhagen, Marine Biological Laboratory, Strandpromenaden 5, 3000 Copenhagen, Denmark
}

\begin{abstract}
The impact of anoxia and anoxia-sulphide (8 different numeric sulphide concentrations, ranging from $10 \mu \mathrm{mol} \mathrm{l}^{-1}$ to $10 \mathrm{mmol} \mathrm{l}^{-1}$ ) on hatching of subitaneous eggs of the planktonic copepod Acartia tonsa Dana was evaluated. The experiments were consequently conducted at pH 8.1. Subitaneous eggs, spawned by laboratory-reared specimens, were exposed to anoxia and anoxia-sulphide for different periods $(3,7,14,30,60,120,180$ and $240 \mathrm{~d})$ and then transferred to normoxic conditions. Short-term ( 3 to $60 \mathrm{~d}$ ) exposure to anoxia or anoxia-sulphide did not significantly affect the hatching success of the eggs, but hatching generally declined with increasing length of exposure. After $60 \mathrm{~d}$ of exposure there were significant differences between the effects caused by anoxia and anoxia-sulphide (sulphide concentrations $\geq 250 \mu \mathrm{mol} \mathrm{l}^{-1}$ ). After $240 \mathrm{~d}$ of exposure there were significant differences in hatching between eggs treated with anoxia and those with anoxia-sulphide (all sulphide concentrations). A short-term experiment, where subitaneous eggs were simultaneously exposed to oxygen and different sulphide concentrations, indicated that sulphide is capable of crossing the eggshell. The metabolic rate of eggs exposed to normoxic conditions was $1.86 \pm 0.57 \mu \mathrm{J} \mathrm{h}{ }^{-1}$. Eggs exposed to anoxia had a metabolic rate of $0.08 \pm 0.02 \mu \mathrm{J} \mathrm{h}^{-1}$, whereas eggs exposed to anoxia and $14.7 \mathrm{mmol} \mathrm{l}^{-1}$ sulphide had a metabolic rate of $0.25 \pm 0.001 \mu \mathrm{J} \mathrm{h}^{-1}$. Based on the metabolism experiments and the fact that internal egg $\mathrm{pH}$ was $\sim 6$, an unknown sulphide defence mechanism is suggested to be present in $A$. tonsa eggs.
\end{abstract}

KEY WORDS: Acartia tonsa $\cdot$ Copepoda $\cdot$ Subitaneous eggs $\cdot$ Anoxia $\cdot$ Sulphide $\cdot$ Survival $\cdot$ Metabolism $\cdot$ Defence mechanism

\section{INTRODUCTION}

Calanoid copepods are prominent members of the zooplankton communities in estuarine and costal regions in terms of numbers, biomass and productivity. Typical boreal estuarine and costal genera include Acartia, Centropages and Labidocera (Marcus \& Lutz 1994). A great majority of marine calanoid copepods spawn their eggs freely into the water column. The eggs are denser than the surrounding seawater and they begin to sink. The eggs may be subitaneous, which normally hatch within a few days, or diapause, which undergo a refractory phase (Grice \& Marcus 1981). In shallow waters, subitaneous eggs may sink to the bottom before hatching if limited vertical turbulence occurs. Once at the seabed, a quiescent state might be induced in the eggs, probably due to low oxy- gen concentrations $\left(<0.15 \mathrm{ml} \mathrm{l}^{-1}\right)$, which inhibits hatching (reviewed by Grice \& Marcus 1981). For the duration of the time that eggs remain buried in the sediment they are likely to be exposed to anoxia. Therefore, viability and development of the benthic resting eggs are greatly influenced by the environmental conditions in the sediment (Uye \& Fleminger 1976). The greatest numbers (e.g. $10^{6} \mathrm{~m}^{-2}$ ) of buried eggs from planktonic copepods occur in estuarine muddy sediment at shallow water depths (Marcus 1996).

In marine environments, the disappearance of oxygen is often correlated with the formation of toxic hydrogen sulphide. When oxygen is absent, first nitrates and then sulphates serve as electron acceptors in the bacterial mineralisation of organic matter. The reduction of sulphates leads to the formation of sulphide and $\mathrm{H}_{2} \mathrm{~S}$. In particular, soft seabeds, which often are poorly 
aerated, are characterised by periods of substantial sulphide production and $\mathrm{H}_{2} \mathrm{~S}$ (Vopel et al. 1998). Marine sediments consist of an upper oxic and deeper anoxic sulphide-containing layer, in which considerable amounts of sulphide (up to $10 \mathrm{mmol} \mathrm{l}^{-1}$ ) may be found at a depth of a few $\mathrm{mm}$ or $\mathrm{cm}$ (Fenchel \& Riedel 1970). Under conditions of reduced oxygen concentrations in the bottom water layer, sulphide may diffuse into the sediment-water interface and cause the overlaying water to become anoxic and sulphidic, thus affecting fauna in the top sediment (Nilsson \& Rosenberg 1994). In aqueous solutions, the equilibrium concentration of the different sulphide species (i.e. $\mathrm{H}_{2} \mathrm{~S}$, $\mathrm{HS}^{-}$and $\mathrm{S}^{2-}$ ) varies with $\mathrm{pH}$. In natural open seawater, the $\mathrm{pH}$ ranges from 7.9 to 8.3 (Hinga 1992, 2002) and the dominant sulphide species is the hydrosulphide anion $\left(\mathrm{HS}^{-}\right)$. In porewater, where $\mathrm{pH}$ can be as low as 6.0 to 6.5 , the dominant species is the natural molecular gas $\mathrm{H}_{2} \mathrm{~S}$ (Vismann 1996a). $\mathrm{H}_{2} \mathrm{~S}$ is capable of crossing biological cell membranes freely, whereas the $\mathrm{HS}^{-}$ anion may be electrically excluded (Bagarinao 1992). The total sulphide toxicity towards marine benthic invertebrates is $\mathrm{pH}$ dependent and increases with decreasing pH (Vismann 1996a).

According to Diaz (2001), hypoxic, anoxic and sulphidic conditions are occurring more frequently in sediments and bottom waters due to increased eutrophication. The survival of copepod eggs exposed to anoxia has been studied by Uye \& Fleminger (1976), Lutz et al. (1992) and Marcus et al. (1994). These studies all indicate that copepod eggs can survive anoxia for days to weeks and, in some cases, years. However, in addition to low oxygen concentrations, copepod eggs are also exposed to hydrogen sulphide in natural anoxic environments. The impact of sulphide on egg viability of planktonic copepods under laboratory conditions has only been studied by Marcus et al. (1997) and Invidia et al. (2004). They both concluded that there was no significant difference in viability between eggs exposed to anoxia-sulphide (at $\mathrm{pH}$ 8.2) and those exposed to anoxia alone. Additionally, at $\mathrm{pH} 6.5$, the exposure of eggs to anoxia-sulphide was more detrimental than when exposed to anoxia alone (Invidia et al. 2004).

The brine shrimp Artemia franciscana is frequently used as a model organism in metabolic studies because the embryos exhibit an astonishing long term tolerance to anoxia. In a number of direct calorimetric experiments, the brine shrimp embryo was shown to be capable of reducing the energy flow to $2.4 \%$ of the aerobic level. For longer periods of anaerobiosis the metabolic depression can extend down to $0.5 \%$ of the aerobic level (Kemp 1999). Whether embryos of Acartia tonsa are equally capable of metabolism depression is not known. Likewise, it is not known whether metabolic depression also occurs under sulphidic conditions.
With the ultimate purpose of discussing the fate of eggs from boreal neritic calanoid copepods that potentially sink before hatching and reach anoxic/sulphidic marine sediments, we performed a series of laboratory experiments. We mimicked a situation where eggs produced by free spawning calanoids during fall are buried in marine sediments, and re-enter the pelagic environment the proceeding spring-summer or even later. We studied the viability of the eggs when exposed to anoxia, and to anoxia plus different sulphide concentrations, for different time periods. The aim of the present study was to assess hatching and viability of Acartia tonsa eggs exposed to anoxia and different sulphide concentrations for different periods of time, and to substantiate the results by measuring the metabolic activity of $A$. tonsa eggs exposed to similar conditions. The present study addressed the following questions: (1) Does sulphide affect the viability of A. tonsa eggs? (2) Do A. tonsa eggs exhibit a minimum tolerance level to sulphide, and does time exposure matter? (3) Does sulphide actually pass through the eggshell? (4) Is metabolism affected when A. tonsa eggs are exposed to anoxia and to anoxia-sulphide? (5) Do A. tonsa eggs have a defence mechanism against or detoxification system for sulphide?

\section{MATERIALS AND METHODS}

Long-term experiment. Sampling and maintenance of cultures: Acartia tonsa eggs used in the experiments came from laboratory cultures that were raised over the last 25 yr under the same conditions (Støttrup et al. 1986). The copepods were cultivated in our laboratory in 70 l tanks filled with seawater ( 30 psu) and covered with opaque plastic. The water temperature was $17 \pm$ $1^{\circ} \mathrm{C}$ and atmospheric air was gently supplied to ensure that algal food remained in suspension. Copepod cultures were fed daily with $1000 \mathrm{ml}$ of a suspension of the chryptophyte Rhodomonas salina (approx. $8 \mu \mathrm{m}$ equivalent spherical diameter) of approximately $10^{6}$ cells $\mathrm{ml}^{-1}$. This gave a mean cell density of approx $15 \times$ $10^{3} \mathrm{ml}^{-1}$, above half-saturation according to Berggreen et al. (1988) and Hansen et al. (1997).

Alga was continuously cultivated in round bottom culture flasks (2 to 5 l) filled with pasteurised natural seawater (30 psu) with added artificial B1-media (Hansen 1989) in a $17 \pm 1^{\circ} \mathrm{C}$ walk-in climate room. The cultures were maintained in logarithmic growth phase, and received approximately $125 \mu \mathrm{E} \mathrm{m} \mathrm{m}^{-2} \mathrm{~s}^{-1}$ of photosynthetic active radiation (PAR) continuously (measured by a Li-Cor LI-1000 Data Logger equipped with a Li-Cor model quantum Serial No. Q30253 sensor).

Experimental procedure: A $0.1 \mathrm{M} \mathrm{NaHCO}$-buffer solution was prepared in $0.2 \mu \mathrm{m}$ GF/F filtered sea- 
water. The buffer was deoxygenated by bubbling vigorously for $1 \mathrm{~h}$ with nitrogen gas, and then by bubbling gently over night. The $\mathrm{pH}$ was adjusted to 8.10 with diluted $\mathrm{HCl}$. The salinity of the buffer-solution was determined to $35.5 \mathrm{psu}$.

Eggs produced within $24 \mathrm{~h}$ were collected from the bottom of the copepod culture tanks with a siphon. After collection, eggs were cleaned through meshes of 3 different sizes $(100,90$ and $70 \mu \mathrm{m})$. Cleaned eggs were finally transferred to screw-capped vials $(20 \mathrm{ml}$, Kimble) by sub-sampling. The sub-sampling was performed with a bottle containing the cleaned eggs and a known volume of seawater, and a $10 \mathrm{ml}$ 'Kip-automat' (NS 29.2/32, Witeg) - a glass device constructed to dose an accurate volume of liquid from a bottle. The sub-sample $(10 \mathrm{ml})$ of the egg-suspension was sieved onto a $45 \mu \mathrm{m}$ mesh that retained the eggs. The mesh and eggs were gently transferred to screw-capped vials. The anoxic vials were filled with anoxic $\mathrm{NaHCO}_{3}$-buffer, creating a surface meniscus. A small piece of household film (Vita Wrap) was gently placed on top to avoid air-bubbles, and the lid was firmly closed. The number of eggs in each vial, regardless of treatment, was $108.9 \pm 5.5$.

A pilot project (data not shown) verified that the $\mathrm{NaHCO}_{3}$-buffer did not affect hatching success of the eggs ( $t$-test, $\mathrm{p}>0.05)$. A control experiment to monitor the viability of the actual egg batch used throughout the long term experiment was conducted in 10 Petri dishes. The total number of eggs in each Petri dish was counted before they were left to hatch for $4 \mathrm{~d}$ at normoxic conditions at $17^{\circ} \mathrm{C}$. Every day, a few drops of Rhodomonas salina suspension were added to feed the newly hatched nauplii, and after $4 \mathrm{~d}$ the number of eggs and nauplii was counted under a dissecting microscope.

Sulphide stock solution ( 0.1 M) was prepared from anhydrous $\mathrm{Na}_{2} \mathrm{~S}$ and $0.2 \mu \mathrm{m} \mathrm{GF} / \mathrm{F}$ filtered seawater, which had been bubbled with nitrogen gas over night. The actual sulphide concentration of the stock solution was determined to be $0.112 \mathrm{M}$ using the Cline method (Cline 1969). The sulphide samples were prepared by adding $15 \mathrm{ml}$ of anoxic $\mathrm{NaHCO}_{3}$-buffer to the vials containing the eggs, and then a suitable aliquot of sulphide stock solution was added to the vials to obtain the numeric sulphide concentrations. The vials were filled and closed the same way as described for the anoxic samples. Before the addition of the required amount of sulphide, only $10 \mathrm{ml}$ of anoxic $\mathrm{NaHCO}_{3}-$ buffer was added to vials with sulphide concentrations of $10 \mathrm{mmol} \mathrm{l}^{-1}$, and finally $\mathrm{pH}$ was adjusted to approximately 8 (via addition of diluted $\mathrm{HCl}$ ). The sulphide concentrations in the vials were only numeric and the actual sulphide concentration in each vial was first determined at the end of the exposure.
Vials were kept in an insulated box filled with water at $17^{\circ} \mathrm{C}$. This temperature was chosen because copepods were cultivated at this temperature and, according to the literature, many experiments on Acartia tonsa were conducted at this temperature. After exposure, oxygen concentrations were measured with an OX50 oxygen microsensor (Unisense). In vials with $10 \mathrm{mmol} \mathrm{l}^{-1}$ sulphide, the oxygen-electrode was poisoned by the sulphide so that the signal indicated $-\infty$. The actual sulphide concentrations in the vials were thus determined using the Cline method (Cline 1969) and the $\mathrm{pH}$ measured with a combined $\mathrm{pH}$-electrode (Radiometer).

Copepod eggs were washed with $0.2 \mu \mathrm{m}$ filtered seawater and counted under a dissecting microscope. Normally no or only a few eggs hatched during the incubation. The eggs were left in Petri dishes with fresh seawater for $4 \mathrm{~d}$ at $17^{\circ} \mathrm{C}$. After $4 \mathrm{~d}$ of normoxic conditions, the number of eggs and nauplii was counted again and hatching success calculated.

The stage of the nauplii after 180 and $240 \mathrm{~d}$ of exposure was determined and categorised as 'stage NIII or higher' or as nauplii at a lower development stage. Eggs and nauplii were kept in antibiotic seawater (Penicillin-Streptomyci: 10000 units $\mathrm{ml}^{-1}$ Penicillin and $10 \mathrm{mg} \mathrm{ml}^{-1}$ Streptomycin in $0.2 \mu \mathrm{m} \mathrm{GF} / \mathrm{F}$ filtered seawater) at normoxic conditions at $17^{\circ} \mathrm{C}$. The hatching success was monitored after $4 \mathrm{~d}$ and then at least every fourth day for 16 and $11 \mathrm{~d}$, respectively. A control experiment was conducted, where the effects of antibiotics on hatching success were examined, and no significant differences were apparent between the hatching success of eggs kept in antibiotic seawater and those in normal seawater (data not shown).

Short-term experiment. In a series of experiments, Acartia tonsa eggs produced within $24 \mathrm{~h}$ were exposed to different sulphide concentrations in the presence of oxygen and at $\mathrm{pH} \sim 8.2$ ( $\mathrm{pH} \sim 8$ in the long-term experiment), in order to study the possible diffusion of hydrogen sulphide $\left(\mathrm{H}_{2} \mathrm{~S}\right)$ across the egg membrane. If the hatching success of eggs exposed to sulphide decreased with increasing sulphide concentrations or exposure time, this would indicate that hydrogen sulphide was capable of crossing the egg membrane. In all experiments, the initial water volume (2 l) was bubbled with atmospheric air for at least 30 min. The experimental computer protocols were controlled by a set-up that simultaneously recorded and controlled $\mathrm{pH}$ and total sulphide (for details, see Vismann 1996b). The eggs were cleaned as earlier described and, via the sub-sampling method described above, transferred to a small cylindrical container ( $25 \mathrm{ml}$ ) equipped with $45 \mu \mathrm{m}$ mesh at both ends, so that they were easy to find after exposure. Exposure time ranged from 2 to $5 \mathrm{~d}$. At the end of experiment, eggs were transferred to Petri dishes 
where the number of eggs and nauplii was counted. Normally no or only a few eggs hatched. After $4 \mathrm{~d}$ of exposure to normoxic conditions at $17^{\circ} \mathrm{C}$, the eggs and nauplii were counted again and hatching success calculated. For every experiment and batch of eggs, a control experiment was conducted in Petri dishes to test hatching success under normoxic conditions.

Internal $\mathbf{p H}$ and buffer capacity measurements. $\mathrm{pH}$ measurements were conducted on 2 different days on a homogenate of approximately 300000 eggs that were 1 and 5 d-old (cold stored, sensu Drillet et al. 2006). Eggs were cleaned as described earlier, collected on a $70 \mu \mathrm{m}$ mesh, and tissues were pressed from below towards the mesh to remove the seawater. The eggs were then transferred to an Eppendorf tube and exposed to liquid nitrogen for $10 \mathrm{~min}$ and defrosted; this procedure was completed 5 times in a row to ensure that all of the eggs were ruptured. The pH-measurements of egg fluids were carried out directly in the Eppendorph tubes with a small $\mathrm{pH}$-electrode (diameter $0.5 \mathrm{~mm}$ ) from Radiometer, and were measured 3 times consecutively for each batch of eggs. The $\mathrm{pH}$ of water from the copepod culture tanks was also measured.

The buffer capacity towards acid and base were conducted separately on 2 batches of eggs: towards acid was measured using a batch of 128000 eggs via titration with $0.01 \mathrm{M} \mathrm{HCl}$, and towards base was measured using a batch of 100000 eggs via titration with $0.0095 \mathrm{M} \mathrm{NaOH}$. A microburette $(200 \mu \mathrm{l})$ was used to add the titrant. The amount of titrant varied from several $\mu \mathrm{l}$ to several $\mathrm{ml}$, depending on the variability of $\mathrm{pH}$. The $\mathrm{pH}$-electrode was used to mix the egg fluids with the titrant.

Metabolism experiments. Experimental procedure: Copepod eggs produced within $24 \mathrm{~h}$ were cleaned as previously described and transferred to a sub-sampling bottle. A known volume of $0.2 \mu \mathrm{m}$ filtered seawater was added, and a control experiment was conducted in Petri dishes to determine hatching success of the actual batch of eggs as well as to provide an estimate of the total amount of eggs incubated. Sub-sampling gave 4 equally sized portions, and the eggs were accumulated on a $70 \mu \mathrm{m}$ mesh. The mesh was pressed from below with tissues in order to remove the seawater (previously described) and afterwards washed with anoxic antibiotic buffer (Penicillin-Streptomycin: 10000 units $\mathrm{ml}^{-1}$ Penicillin and $10 \mathrm{mg} \mathrm{ml}^{-1}$ Streptomycin in $\mathrm{GF} / \mathrm{F}$ filtered $\mathrm{NaHCO}_{3}$-buffer) for approximately $5 \mathrm{~min}$, and again pressed with tissues.

Isothermal microcalorimetry: Calorimetry is a nonspecific technique for the direct measurement of metabolic activity, and is used for the direct determination of heat quantities and of heat production rates or thermal powers. All calorimetric measurements were conducted on type 2277 thermal activity monitors (TAM) from Thermometric. The sample was loaded into a $3 \mathrm{~cm}^{-3}$ stainless steel calorimetric vessel. For samples exposed to oxygen or sulphide, the calorimetric vessel was mounted on a type 2250 perfusion calorimetry module (Thermometric). Throughout the thermal equilibration and data acquisition periods, the sample was stirred by a turbine stirrer at $60 \mathrm{rpm}$, to ensure a constant supply of oxygen or equal distribution of sulphide to the eggs. To thermally equilibrate the sample $\left(17^{\circ} \mathrm{C}\right)$, it was gradually lowered into the calorimeter over a period of 60 to $120 \mathrm{~min}$. At this stage, the data collection was initiated and monitored for 15 to $38 \mathrm{~h}$. The experiments conducted in the TAM were kept at $17^{\circ} \mathrm{C}$ and the baseline value for each channel was measured (data not shown). The baselines represented the amount of heat produced in the channel when there were no contributions from any biological or chemical processes involved. Negative baselines were added to measured signals from the experiments, whereas positive baselines were subtracted from measured signals in order to take baseline levels into account. After the TAM measurements were conducted, oxygen concentrations in the TAM vessels were determined by the Unisense oxygen microsensor (OX50). Oxygen concentration was determined to be $0.002 \pm 0.004 \mathrm{ml} \mathrm{O}_{2} \mathrm{l}^{-1}$ for anoxic experiments, and 3.67 $\pm 0.25 \mathrm{ml} \mathrm{O}_{2} \mathrm{l}^{-1}$ for normoxic experiments, ensuring no oxygen limitation during measurement.

For the anoxic experiments, eggs were transferred to the TAM vessel, $2 \mathrm{ml}$ of the anoxic Penicillin/Streptomycin solution was added, and the egg suspension was bubbled with nitrogen gas for 5 to 10 min during which time the vessel was covered with Parafilm. Afterwards, a small chink between the vessel and the lid was left open and a gentle stream of argon gas was supplied for 1 to $2 \mathrm{~min}$ in order to remove oxygen from the gas phase above the sample.

Experiments on anoxia-sulphide followed the same procedure as above, except that $300 \mu \mathrm{l}$ of a sulphide stock solution was added so that actual sulphide concentration in the TAM vessel was $14.7 \mathrm{mmol}^{-1}$. A high sulphide concentration ensured that the sulphide concentration was sufficient to have an influence on the metabolism of the eggs.

The aerobic experiments followed the same procedure, with the exception that egg suspensions were bubbled with atmospheric air instead of nitrogen for 5 to $10 \mathrm{~min}$ and then the TAM vessels were closed.

All TAM vessels were sealed with an O-ring and cleaned with ethanol before they were lowered into the TAM, and thermostated before measurements were initiated.

Data analysis. Each vial was considered to be a replicate for data analysis of egg hatching. The final hatching percentage for each vial was arc-sin transformed, 
because data are expressed as percentages. Means and SD were calculated from the transformed values for each incubation period and for each collection date.

\section{RESULTS}

\section{Long-term experiment}

The oxygen concentration in vials ranged from 0.0 to $0.76 \mathrm{ml} \mathrm{O}_{2} \mathrm{l}^{-1}$ throughout all treatments and over time. From $30 \mathrm{~d}$ onwards, oxygen concentrations slightly decreased to between 0.0 and $0.09 \mathrm{ml} \mathrm{O}_{2} \mathrm{l}^{-1}$. The final oxygen concentration in most of the 296 vials was less than 0.02 and approached $0.0 \mathrm{ml} \mathrm{O}_{2} \mathrm{l}^{-1}$.

The actual sulphide concentrations in the 10, 25 and $50 \mu \mathrm{mol} \mathrm{l}^{-1}$ sulphide experiments were very close to one another (Table 1); in reality, the difference between the
3 sulphide concentrations was less than $5 \mu \mathrm{mol} \mathrm{l}^{-1}$. Therefore, hatching success under these 3 sulphide concentrations was pooled (Fig. 1). In general, the actual sulphide concentrations were lower than the intended concentrations. The actual sulphide concentrations showed a decrease with increasing incubation time (Table 1).

Mean $\mathrm{pH}$ in vials changed from 8.14 to 8.46 , but a significant difference was only observed between vials exposed for $7 \mathrm{~d}$ and $240 \mathrm{~d}$ (ANOVA, p < 0.00000).

\section{Hatching success}

The batch of copepod eggs used had a hatching success of $75 \%$ when they were kept at $17^{\circ} \mathrm{C}$ for $4 \mathrm{~d}$ under normoxic conditions (control). No hatching occurred during either anoxia or sulphide treatments, irrespec-

Table 1. Acartia tonsa. Actual mean sulphide concentrations \pm SD in vials at different exposure times reported under numeric sulphide concentrations. No. of replicates $=5$, except for Days 3 and 180 where no. of replicates $=1$

\begin{tabular}{|ccccccccc}
\hline \multirow{2}{*}{$\begin{array}{c}\text { Exposure } \\
\text { (d) }\end{array}$} & $10 \mathrm{l}^{-1}$ & $25 \mathrm{l}^{-1}$ & $50 \mathrm{l}^{-1}$ & $100 \mathrm{l}^{-1}$ & $250 \mathrm{l}^{-1}$ & $500 \mathrm{l}^{-1}$ & $1000 \mathrm{l}^{-1}$ & $10000 \mathrm{l}^{-1}$ \\
\hline 3 & 15 & 17 & 20 & 130 & 235 & 535 & $586^{\mathrm{a}}$ & $2670^{\mathrm{a}}$ \\
7 & $2 \pm 1$ & $5 \pm 5$ & $9 \pm 7$ & $57 \pm 24$ & $155 \pm 120$ & $856 \pm 73$ & $1592 \pm 78$ & $629 \pm 112$ \\
14 & $3 \pm 3$ & $5 \pm 4$ & $7 \pm 4$ & $60 \pm 24$ & $296 \pm 235$ & $622 \pm 182$ & $1029 \pm 69$ & $2187 \pm 116$ \\
30 & $4 \pm 2$ & $8 \pm 6$ & $7 \pm 4$ & $24 \pm 8$ & $186 \pm 15$ & $456 \pm 272$ & $1326 \pm 109$ & $4119 \pm 124$ \\
60 & $2 \pm 1$ & $4 \pm 4$ & $5 \pm 7$ & $35 \pm 15$ & $122 \pm 65$ & $283 \pm 212$ & $999 \pm 71$ & $4448 \pm 116$ \\
120 & $3 \pm 1$ & $2 \pm 1$ & $4 \pm 4$ & $45 \pm 53$ & $95 \pm 67$ & $381 \pm 124$ & $696 \pm 193$ & $6897 \pm 457$ \\
180 & 0.4 & 2 & 2 & 7 & 11 & 46 & 1656 & 1922 \\
240 & $2 \pm 1$ & $14 \pm 17$ & $5 \pm 4$ & $4 \pm 3$ & $26 \pm 39$ & $132 \pm 137$ & $302 \pm 251$ & $1854 \pm 221$
\end{tabular}

aSamples were not sufficiently diluted; therefore not all sulphide required was bound in the methylene blue-complex, which led to an under-estimation of sulphide concentrations
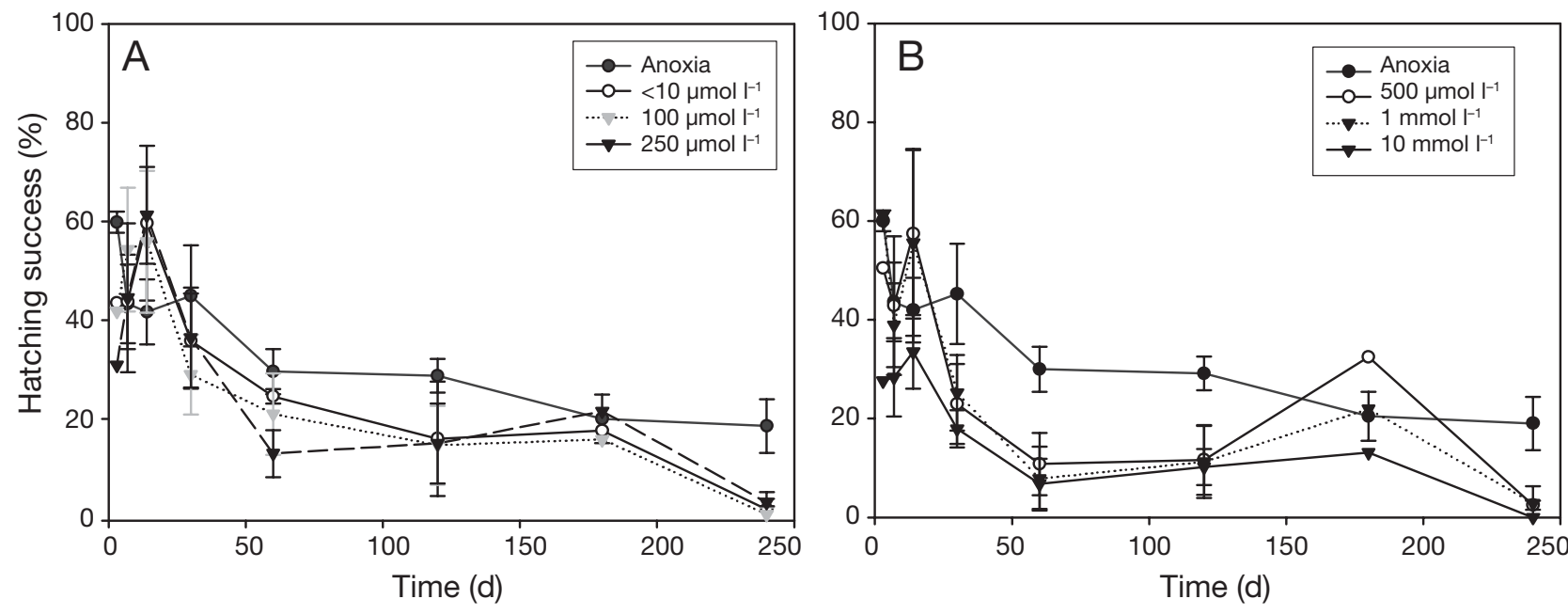

Fig. 1. Acartia tonsa. Long-term experiment: mean \pm SD hatching success of subitaneous eggs exposed to anoxia and different sulphide concentrations. (A) Anoxia and numeric sulphide concentrations from 10 to $250 \mu \mathrm{mol} \mathrm{l}^{-1}$ (NB: hatching success in numeric sulphide concentrations from 10 to $50 \mu \mathrm{mol} \mathrm{l}^{-1}$ was pooled). (B) Anoxia and numeric sulphide concentrations from $500 \mu \mathrm{mol} \mathrm{l}^{-1}$ to $10 \mathrm{mmol} \mathrm{l}^{-1}$ 
tive of exposure time. The eggs resumed hatching only after transfer to normoxic seawater.

Egg viability was variable in the anoxia and sulphide vials, but generally declined with increasing length of exposure (Fig. 1). Under anoxic conditions, hatching success decreased from $60 \%$ after 3 d to $19 \%$ after $240 \mathrm{~d}$ of incubation, and from $27.6 \%$ after $3 \mathrm{~d}$ to $0 \%$ after $240 \mathrm{~d}$ of incubation when exposed to the highest sulphide concentration.

There was no significant difference between the hatching success of eggs exposed to anoxic conditions and that of eggs exposed to all sulphide concentrations when exposure was shorter than $60 \mathrm{~d}$. However, at $60 \mathrm{~d}$ there was a significant difference between the hatching success of eggs exposed to anoxia and those exposed to sulphide concentrations $\geq 250 \mu \mathrm{mol} \mathrm{l}^{-1}$ (ANOVA, $\mathrm{p}=0.05$ ). After $120 \mathrm{~d}$, there was a significant difference between hatching success of eggs exposed to anoxia and of those exposed to sulphide concentrations $\geq 500 \mathrm{\mu mol} \mathrm{l}^{-1}$. After $240 \mathrm{~d}$ of incubation, the hatching success of all eggs exposed to all sulphide concentrations reached a level below $5 \%$, and sulphide concentrations of $10 \mu \mathrm{mol} \mathrm{l}^{-1}$ none of the eggs hatched. There were significant differences between hatching rates of eggs exposed to all sulphide concentrations and of those exposed to anoxia (ANOVA, $\mathrm{p}=$ $0.05)$. A 2 -factor ANOVA showed that the effect of sulphide $(p \leq 0.000000)$, time $(p \leq 0.000000)$, and the interactions between sulphide and time was very strong ( $p \leq 0.000002)$. Hence, increasing sulphide concentrations had a significant effect on egg hatching success, and this effect increased over time.

\section{Stage development}

The viability of eggs incubated under anoxic conditions for 180 and $240 \mathrm{~d}$ and then left for $4 \mathrm{~d}$ in normoxic conditions had a hatching success of 12.2 and $1.1 \%$, respectively. Hatching successes were calculated again after $16 \mathrm{~d}$ (eggs exposed for $180 \mathrm{~d}$ ) and $11 \mathrm{~d}$ (eggs exposed for $240 \mathrm{~d}$ ) in normoxic conditions, and increased further to 19.3 and $1.8 \%$, respectively. A smaller fraction of nauplii (hatched from eggs incubated under anoxic conditions for 180 and 240 d) reached the NIII stage when eggs were exposed to high sulphide concentrations (Table 2).

\section{Short-term experiment}

Mean \pm SD pH ranged from $8.2 \pm 0.1$ to $8.3 \pm 0.1$ in all experiments. All sulphide measurements (in $\mathrm{mV}$ ) were very close to the sulphide set-point and exhibited very little variation in $\mathrm{SD}$, which indicated that the eggs had
Table 2. Acartia tonsa. No. of nauplii at stage $<$ NIII or $\geq$ NIII, and $\% \geq$ NIII nauplii (of total) after (A) 180 and (B) $240 \mathrm{~d}$ of incubation in anoxia and different numeric sulphide concentrations

\begin{tabular}{|lcccc|}
\hline Sulphide $\left(\mu \mathrm{mol} \mathrm{l}^{-1}\right)$ & Total & $<$ NIII & $\geq$ NIII & $\geq$ NIII\% \\
\hline (A) & & & & \\
Anoxia & 12 & 3 & 9 & 75 \\
10 & 10 & 0 & 10 & 100 \\
25 & 4 & 3 & 1 & 25 \\
50 & 4 & 0 & 4 & 100 \\
100 & 16 & 9 & 7 & 44 \\
250 & 6 & 3 & 3 & 50 \\
500 & 5 & 4 & 1 & 20 \\
$10^{3}$ & 8 & 8 & 0 & 0 \\
$10^{4}$ & 2 & 2 & 0 & 0 \\
& & & & \\
$(B)$ & & & & \\
Anoxia & 15 & 4 & 11 & 73 \\
10 & 13 & 3 & 10 & 77 \\
25 & 8 & 3 & 5 & 63 \\
50 & 13 & 4 & 9 & 69 \\
100 & 7 & 5 & 2 & 29 \\
250 & 14 & 10 & 4 & 29 \\
500 & 12 & 8 & 4 & 33 \\
$10^{3}$ & 12 & 10 & 2 & 17 \\
$10^{4}$ & 0 & 0 & 0 & 0 \\
& & & & \\
\hline
\end{tabular}

Table 3. Acartia tonsa. Mean $\mathrm{pH} \pm \mathrm{SD}$, temperature $\pm \mathrm{SD}$, sulphide \pm SD and sulphide set-point for short-term experiments

\begin{tabular}{|rlclc|}
\hline $\begin{array}{c}\text { Sulphide } \\
\left(\mu \mathrm{mol} \mathrm{l}^{-1}\right)\end{array}$ & $\mathrm{pH}$ & $\begin{array}{c}\text { Temperature } \\
\left({ }^{\circ} \mathrm{C}\right)\end{array}$ & $\begin{array}{c}\text { Measured } \\
(\mathrm{mV})\end{array}$ & $\begin{array}{c}\text { Set-point } \\
(\mathrm{mV})\end{array}$ \\
\hline 55.9 & $8.2 \pm 0.1$ & $17.0 \pm 0.1$ & $-549.2 \pm 14.0$ & -532 \\
108.8 & $8.2 \pm 0.1$ & $16.8 \pm 0.1$ & $-549.7 \pm 5.2$ & -545 \\
393.4 & $8.3 \pm 0.03$ & $16.8 \pm 0.1$ & $-563.4 \pm 3.6$ & -560 \\
$1.2 \times 10^{3}$ & $8.3 \pm 0.2$ & $17.1 \pm 0.1$ & $-567.8 \pm 5.3$ & -565 \\
$6.4 \times 10^{3}$ & $8.3 \pm 0.1$ & $16.8 \pm 0.1$ & $-567.1 \pm 0.3$ & -566 \\
$12.8 \times 10^{3}$ & $8.3 \pm 0.3$ & $17.1 \pm 0.1$ & $-579.7 \pm 4.3$ & -580 \\
$22.5 \times 10^{3}$ & $8.3 \pm 0.1$ & $17.0 \pm 0.1$ & $-616.0 \pm 2.0$ & -615 \\
& & & & \\
\hline
\end{tabular}

been exposed to constant sulphide concentrations during the entire incubation (Table 3).

Hatching success generally declined with increasing sulphide concentrations and exposure time (Fig. 2). There was a significant difference between hatching success in the control and the anoxic treatment, as well as between the control and all sulphide concentration treatments (ANOVA, $p=0.05$ ). A significant difference in hatching success was observed between anoxia and sulphide concentrations $\geq 1.2 \mathrm{mmol}^{-1}$ after $2 \mathrm{~d}$, whereas hatching success of eggs exposed to low sulphide concentrations did not differ from those exposed to anoxia (ANOVA, $p=0.05$ ). Decreasing hatching success with increasing sulphide concentration and exposure time indicated that the hydrogen sulphide was capable of crossing the egg membrane. 


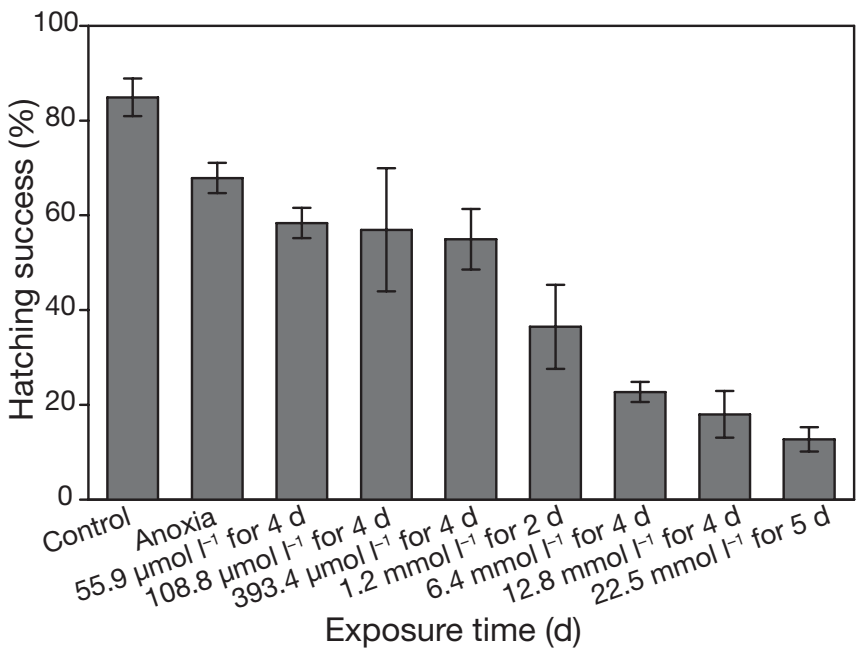

Fig. 2. Acartia tonsa. Short-term experiment: mean \pm SD hatching success of subitaneous eggs exposed to oxygen and different sulphide concentrations (simultaneously) for different time periods (5 replicates each). After exposure, eggs were maintained under normoxic conditions for $4 \mathrm{~d}$ before hatching success was calculated

\section{Internal pH and buffer capacity}

The internal mean $\mathrm{pH}$ of 1 and 5 d-old Acartia tonsa eggs maintained under normoxic conditions was 6.09 and 6.07, respectively, and $\mathrm{pH}$ of water from the copepod culture tanks was $7.39 \pm 0.13(\mathrm{n}=8)$. None of the experiments on buffer capacity indicated that $A$. tonsa eggs had any buffer capacity towards acid or to base (data not shown).

\section{Metabolism experiments}

Examples of replicate measurements of the TAM signals of heat production of Acartia tonsa eggs under different experimental conditions are shown in Fig. 3.
The number of eggs in the 4 experiments were not the same, differing from 12600 eggs under normoxic conditions, 45600 eggs each under control and anoxic/sulphidic conditions, and finally 130000 eggs under anoxic conditions. The control measurement was taken from $A$. tonsa eggs that had been heat-killed at $60^{\circ} \mathrm{C}$ for 10 to $15 \mathrm{~min}$ and served as a biological blind-value.

Heat production (mean \pm SD $\mu \mathrm{J} \mathrm{egg}^{-1} \mathrm{~h}^{-1}$, where $1 \mu \mathrm{W}$ $=1 \mathrm{\mu} \mathrm{s}^{-1}$ ) for a single copepod egg under each treatment was as follows: oxygen: $1.86 \pm 0.57(\mathrm{n}=8)$; anoxic: $0.08 \pm$ $0.02(\mathrm{n}=4)$; anoxic-sulphidic $\left(14.7 \mathrm{mmol} \mathrm{l}^{-1}\right)$ : $0.25 \pm 0.001$ $(\mathrm{n}=2)$; control: $0.03 \pm 0.01(\mathrm{n}=2)$. Acartia tonsa eggs exposed to normoxic conditions had a metabolic activity that was almost 7.5 times higher than that of eggs exposed to sulphide. Eggs exposed to anoxia-sulphide produced more than 3 times as much heat as eggs exposed to anoxia alone.

\section{DISCUSSION}

\section{Long- and short-term experiments}

The copepod eggs used in the experiments were subitaneous, as demonstrated by the generally high hatching success of the controls within $4 \mathrm{~d}$. The eggs that failed to hatch were considered to be non-viable, and not, in fact, diapause eggs as described in previous observations (Drillet et al. 2006). Exposure to anoxia and sulphide induced quiescence in the subitaneous eggs of Acartia tonsa, but the eggs were able to resume hatching after recovery under normoxic conditions. The hatching success of eggs incubated for 180 and $240 \mathrm{~d}$ only increased slightly when the eggs were maintained under normoxic conditions for $>4 \mathrm{~d}$; therefore, the general hatching successes calculated after $4 \mathrm{~d}$ were considered to be the final hatching success. However, in all experimental conditions, egg viability first declined, then increased, before slowly decreas-
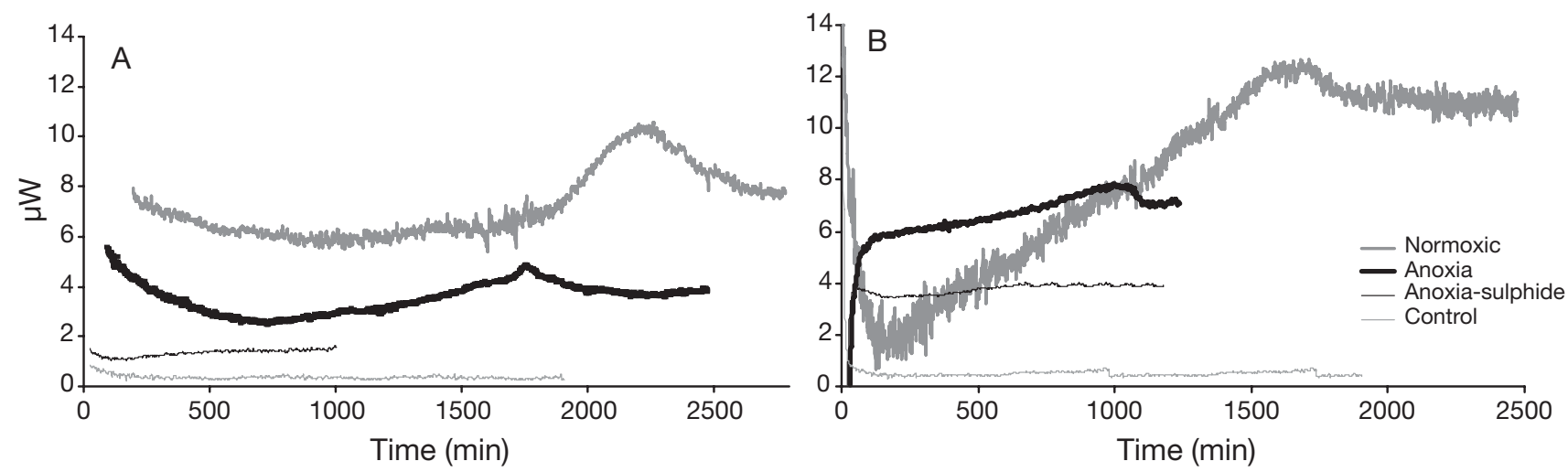

Fig. 3. Acartia tonsa. TAM thermograms of heat production of subitaneous eggs exposed to different conditions. (A) and (B) show TAM thermograms for 2 different replicates. No. of eggs in each measurement varies (see text) 
ing again with increasing exposure time and increasing sulphide concentrations. The pattern of declining egg viability (after 3 to $7 \mathrm{~d}$ of exposure) and then increasing egg viability (after 7 to $14 \mathrm{~d}$ of exposure) was an unexpected result, and we have no explanation for this pattern in egg viability. After 60, 120 and $240 \mathrm{~d}$ incubation periods, significant declines in hatching success were observed. Marcus \& Lutz (1994), Marcus et al. (1997) and Invidia et al. (2004) found that hatching success of $A$. tonsa eggs exposed to anoxia or anoxia-sulphide declined with increasing exposure time, and that after the maximum exposure time of $32 \mathrm{~d}$ some eggs were still viable in all experimental conditions. Our hatching results from the first $30 \mathrm{~d}$ of incubation were within the range of values reported by the above-cited studies.

Comparison of the effects of anoxia and sulphide on the viability of eggs did not show significant differences when exposure time was $<60 \mathrm{~d}$. However, at Day 60 the hatching success of eggs exposed to anoxia was significantly higher than that of eggs exposed to sulphide concentrations $\geq 250 \mu \mathrm{mol}^{-1}$. As the incubation was prolonged, significant differences between the hatching success of eggs exposed to anoxia and to different sulphide concentrations became even more pronounced, and after $240 \mathrm{~d}$ there were significant differences between hatching success after exposure to anoxia and to all sulphide concentrations.

The long-term experiment was supported by results obtained from the short term experiment, where egg viability decreased with increasing sulphide concentrations and exposure time. At low sulphide concentrations $\leq 393.4 \mu \mathrm{mol} \mathrm{l}^{-1}$ there was no significant difference between the hatching successes of eggs exposed to anoxia or to sulphide, whereas there was a significant difference in hatching success after a 2d-exposure to sulphide concentrations $\geq 1.2 \mathrm{mmol} \mathrm{l}^{-1}$. Lutz et al. (1994) suggested that 'perhaps prolonged exposure to low oxygen concentrations, as opposite to zero oxygen, is more detrimental to the eggs because in the absence of oxygen, metabolism is shut down completely, whereas under low oxygen conditions some metabolic functions proceed'. Survival under stress depends on the overall reduction in metabolic rate required to conserve substrates and reduce the accumulation of toxic end-products, and is known as 'metabolic rate depression' (Clegg 1997). Our results from exposures $<60 \mathrm{~d}$ are consistent with this. The addition of sulphide to the vials resulted in complete anoxia from the beginning of the exposure, whereas in 'anoxia' vials we cannot exclude the possibility that there were traces of oxygen present at the beginning of the incubation period. The depression in metabolic rate might have been greater in vials with sulphide than in anoxia vials. Subsequently, cell poisoning was perhaps retarded in the lat- ter treatment because while eggs exposed to sulphide immediately switched to anaerobic metabolism, eggs exposed to anoxia might have begun with aerobic metabolism and then switched to anaerobic metabolism later on. Our results appear to be consistent with those available in the literature: Marcus et al. (1997) reported that there were no significant differences in viability of eggs from 3 calanoid copepod species Acartia tonsa, Labidocera aestiva and Centropages hamatus exposed to anoxia-sulphide and to anoxia alone, and Invidia et al. (2004) reported no significant difference in viability of laboratory-produced A. tonsa eggs exposed to anoxia-sulphide (at $\mathrm{pH} 8.2$ and 6.5) and anoxia alone after $15 \mathrm{~d}$. Both studies suggested that eggs exposed to anoxia-sulphide or prolonged exposure to anoxia survived because the eggs had switched to anaerobic metabolism. In our longterm experiment, eggs were incubated for a much longer period than in studies conducted by Marcus et al. (1997) and Invidia et al. (2004). Our results showed that exposure of $A$. tonsa eggs to sulphide over a relatively short time period $(<60 \mathrm{~d})$ did not result in significant differences between hatching successes of eggs exposed to sulphide and of those exposed to anoxia alone. For medium exposure times (60 to $180 \mathrm{~d}$ ), there were significant differences between hatching successes of eggs exposed to anoxia and to those exposed to sulphide concentrations $\geq 250 \mu \mathrm{mol} \mathrm{l}^{-1}$, and even low sulphide concentrations had a significant effect on hatching success compared to anoxia when eggs were incubated for $240 \mathrm{~d}$.

Egg viability only appeared to be affected by sulphide when exposure time was $\geq 60 \mathrm{~d}$, and hatching was almost completely inhibited after $240 \mathrm{~d}$ of exposure regardless of the sulphide concentration. Invidia et al. (2004) showed that sulphide exposure $(0.78$ to $1.12 \mathrm{mmol} \mathrm{l}^{-1}$ ) for $\leq 15 \mathrm{~d}$ did not appear to be toxic to Acartia tonsa eggs, irrespective of $\mathrm{pH}$. Sulphide toxicity became evident only after $32 \mathrm{~d}$ of exposure at $\mathrm{pH}$ 6.5, but the reduction in hatching success was not significantly different from that of eggs exposed for anoxia alone.

Studies of benthic invertebrates (Vismann 1990, Vismann \& Hagerman 1996, Hagermann 1998) indicated that exposure to hypoxia/anoxia plus sulphide was more detrimental to the organisms than that of exposure to hypoxia or anoxia alone. Vismann \& Hagerman (1996) and Hagerman (1998) suggested that when organisms were exposed to sulphide, the metabolic rate was not dramatically reduced because sulphide detoxification systems were required even under anaerobic conditions. The results from our long-term experiment contradict these studies when exposure time was $<60 \mathrm{~d}$, but supported these studies when exposure time was $\geq 60 \mathrm{~d}$. This suggests that Acartia 
tonsa eggs have some kind of protection to resist even high sulphide concentrations for a period of 30 to $60 \mathrm{~d}$. Bagarinao (1992) reported that there is no evidence of marine animals being able to exclude sulphide at the body membrane. The fact that the tissue diffusion coefficient of $\mathrm{H}_{2} \mathrm{~S}$ is very similar to that of $\mathrm{O}_{2}$ (Powell 1989) led Vopel et al. (1998) to suggest that equilibrium between external and internal sulphide concentrations in small-sized organisms should be reached within a few hours. As suggested by Invidia et al. (2004), the presence of an eggshell capable of blocking entry of sulphide, comparable to that of an adult organism's epithelium, might explain the high tolerance of A. tonsa eggs to sulphide. The short term experiment in the present study suggests that sulphide passes through the eggshell, and internal egg sulphide concentrations is expected to increase slowly as a function of exposure time and external molecular $\mathrm{H}_{2} \mathrm{~S}$ concentration. Only when eggs were exposed for a relatively long time to high $\mathrm{H}_{2} \mathrm{~S}$ concentrations could the internal sulphide reach a level where toxic effects were observed (Invidia et al. 2004).

\section{pH and buffer capacity}

The measured internal pH (6.09 and 6.07) in Acartia tonsa eggs was very low compared to that of other organisms; for instance, the internal pH of different invertebrates was determined by Roos \& Boron (1981) to range from 7 to 8 . The very low internal $\mathrm{pH}$ in the eggs might have resulted from peroxisomes that were unintentionally ruptured during exposure to liquid nitrogen: peroxisomes have a pH of 5 to 6 (Alberts 2002) and their rupture would cause a seepage of $\mathrm{H}^{+}$that would lower the internal $\mathrm{pH}$ of the eggs. On the other hand, an internal $\mathrm{pH}$ of 6 might not be an experimental artefact because the yolk, which has a high content of the lipid triacylglycerol (Lee et al. 2006), is hydrolyzed during embryogenesis to fatty acids. Fatty acids have a low $\mathrm{pH}$ of approximately 6.5 , and their presence might result in an internal $\mathrm{pH}$ within the range of 6 to 7 .

Why do Acartia tonsa eggs have such a low internal $\mathrm{pH}$-value compared to other organisms? An explanation could be that low internal $\mathrm{pH}$ in eggs could serve as a defence mechanism towards sulphide. Based upon theoretical considerations, Groenendaal (1981) suggested that lowering the internal $\mathrm{pH}$ of an organism could serve as a passive protection mechanism to reduce sulphide influx into the organism's tissues. $\mathrm{H}_{2} \mathrm{~S}$ dissociates into $\mathrm{HS}^{-}$and $\mathrm{H}^{+}$, depending on the $\mathrm{pH}$ of the medium. $\mathrm{H}_{2} \mathrm{~S}$ diffuses across biological membranes much faster than does $\mathrm{HS}^{-}$(Bagarinao 1992), and penetrates into the organism until an equilibrium with external $\mathrm{H}_{2} \mathrm{~S}$ concentration is established. Within the organism, the dissociation is shifted towards the $\mathrm{H}_{2} \mathrm{~S}$ fraction due to lower internal $\mathrm{pH}$. This will reduce the influx of $\mathrm{H}_{2} \mathrm{~S}$ across the eggshell membrane and will result in a lower internal total sulphide concentration in comparison to the external concentration. If internal $\mathrm{pH}$ is lowered enough relative to the external $\mathrm{pH}$, the internal total sulphide concentration might be effectively reduced (Sommer et al. 2000).

Eggs from copepod species that live in estuaries are exposed to the risk of becoming buried in the sediment, where the $\mathrm{pH}$ might be as low as 6.0 to 6.5 (Vismann 1996a). An internal pH of approximately 6.1, as measured in Acartia tonsa eggs, would reduce the influx of $\mathrm{H}_{2} \mathrm{~S}$ into the eggs and could thus represent an effective protection against sulphide, or may even be a result of a detoxification mechanism. We hypothesise that low internal $\mathrm{pH}$ contributes to the fact that toxic effects were only observed when eggs were exposed to $\mathrm{H}_{2} \mathrm{~S}$ for a long time. However, this remains to be proven.

Results from the buffer capacity measurements were somewhat uncertain, because the $\mathrm{pH}$-electrode had to be lifted out of the egg matrix fluid to allow room for addition of the titrant. Every time the pH-electrode was separated from the measurement fluid, the $\mathrm{pH}$ reading was influenced. Therefore, buffer capacity results must only be considered to be an indication and not as fact. However, these tentative results suggest no buffer capacity in subitaneous Acartia tonsa eggs, and should be thoroughly investigated in future studies.

\section{Stage development}

A smaller fraction of nauplii that hatched from eggs incubated under anoxic conditions for 180 and $240 \mathrm{~d}$ reached the NIII stage when eggs had been exposed to high sulphide concentrations. The nauplii were only categorised as having reached the NIII stage or not. There was no further examination of whether or not they were capable of reaching adulthood. According to Invidia et al. (2004), incubation of eggs at or close to anoxia did not affect the survival of organisms hatching from the exposed eggs. However, exposure to sulphide at $\mathrm{pH} 6.5$ resulted in death at the naupliar stage of the few hatched organisms. After $32 \mathrm{~d}$ of exposure at $\mathrm{pH}$ 8.2, the internal sulphide concentration might have reached a sublethal level that affected survival and ontogenetic development of nauplii, whereas at $\mathrm{pH} 6.5$ the internal sulphide concentration probably reached a level where hatching success was close to zero. Invidia et al. (2004) suggested that differences in the accumulation of toxic end products during quiescence or sublethal toxic effects of sulphide could account for these observations. In near anoxic conditions, selection was reported to occur at the egg stage. The few eggs 
that survived in Invidia et al.'s (2004) study had the highest tolerance and were able to develop into adulthood. In sulphidic conditions, accumulation of toxic end products was lower and reached a sublethal level. They also suggested that a $15 \mathrm{~d}$ period might be a threshold time during which adaptation mechanisms required to overcome exposure to near anoxia and sulphide become close to exhausted, owing to their observations that the ability to withstand the cost of quiescence became severely reduced. Our results did not support this hypothesis: our results indicated that this threshold time was not reached until between 120 and $240 \mathrm{~d}$ of exposure. It must be taken into account that our study did not examine larval (which reached stage NIII) ability to reach adulthood. The NIII stage is a stage where all nauplii are phagotrophic and no longer dependent on the amount of nutrients provided by the egg yolk (Berggreen et al. 1988, Mauchline 1998).

\section{Metabolism experiments}

Results obtained by the TAM were conducted in real time and represented the actual metabolism for specific batches of Acartia tonsa eggs during a defined time period. A. tonsa eggs that were exposed to normoxic conditions produced the highest amount of heat in the TAM, whereas heat-killed eggs produced the lowest amount. This was as expected, because the heat-killed eggs were considered to be a biological blind-value. However, it was a surprise that $A$. tonsa eggs exposed to anoxia and $14.7 \mathrm{mmol} \mathrm{l}^{-1}$ sulphide produced more heat than eggs exposed to anoxia alone. Hence, the depression in metabolic rate observed in $A$. tonsa eggs exposed to anoxia was not sustained when eggs were exposed to $14.7 \mathrm{mmol} \mathrm{l}^{-1}$ sulphide. According to the long term experiment, we expected eggs exposed to sulphide to have a lower metabolic activity because we believed that the metabolic rate depression would be greater when eggs were exposed to anoxia-sulphide compared to anoxia alone (Marcus et al. 1997, Invidia et al. 2004). The TAM results indicated that sulphide was capable of diffusing into $A$. tonsa eggs. This was verified by our short term as well as long term experimental data, and in the former caused only a minor reduction in the metabolic rate compared to normoxic conditions. The relatively high heat signal was probably due to sulphide detoxification mechanisms that were needed during anaerobic conditions, as suggested by Vismann \& Hagerman (1996) and Hagerman (1998) for crustaceans.

If we tentatively extrapolate the calculated per hour heat production from our measurements, and assume that under normoxic conditions 1 Acartia tonsa egg produces a constant amount of heat (a proxy for metabolism) during its entire embryogenesis, we obtain a total heat production of $1.86 \mu \mathrm{J} \times 36.7=68.2 \mu \mathrm{J}$ per egg (development time considered to be $36.7 \mathrm{~h}$ at $17^{\circ} \mathrm{C}$ [Drillet 2003]). If we assume that this heat production represented all the energy stored in the egg yolk, it would take 1 egg maintained under anoxic conditions $37.6 \mathrm{~d}$ to metabolise the same amount of energy. For 1 egg exposed to $14.7 \mathrm{mmol} \mathrm{l}^{-1}$ sulphide and anoxia it would only require $11.5 \mathrm{~d}$, approximately a one-third reduction compared to eggs exposed to anoxia alone. We question why eggs exposed to sulphide or anoxia alone for $<60 \mathrm{~d}$ in the present long-term experiment, as well as in the studies conducted by Marcus et al. (1997) and Invidia et al. (2004) (where eggs were exposed for $32 \mathrm{~d}$ ), did not show any toxic effects, whereas the TAM results showed that eggs exposed to sulphide clearly had a higher metabolism? The fact that the sulphide concentration in the TAM experiment was more than 2 times higher than the highest sulphide concentration measured in the long-term experiment might explain the higher metabolism of eggs exposed to sulphide. However, when taking into account the fact that exposure to sulphide concentrations of only several $\mu \mathrm{M}$ is lethal for aerobic species without special detoxification mechanisms (Fenchel \& Finlay 1995), sulphide concentrations higher than $100 \mu \mathrm{M}$ (and perhaps even lower) in the present long-term experiment should have had a notable effect on the hatching success of $A$. tonsa eggs. Unfortunately, no control experiment (where only sulphide and no eggs were added to the anoxic antibiotic $\mathrm{NaHCO}_{3}$-buffer) was conducted. Nevertheless, the shape of the thermogram in Fig. 3 demonstrated an almost constant heat production over time, which strongly indicates that heat production was constant during the experiment.

If heat production was a result of chemical reactions between sulphide and the $\mathrm{NaHCO}_{3}$-buffer, and not due to biological activity, it would demand that the chemical reactions proceed with constant slow kinetics during the entire experiment, which is not considered to be plausible (P. West pers. comm.). In conclusion, the heat signals of sulphide-exposed eggs are considered to reflect the metabolism of the eggs. Before the measurements were conducted, the vessels were thermostated for 60 to $120 \mathrm{~min}$. During this period, the heat signals of anoxic treatments might have been initially a little higher because the eggs might not have switched to anaerobic metabolism immediately. For the anoxicsulphidic vessels, the heat signal might also have been higher during this period if the eggs have an acute detoxification system that proceeds at a higher rate at the beginning of exposure. For normoxic vessels, we do not expect higher metabolism at the beginning compared to the rest of the exposure time. 
Acartia tonsa is a typical species of eutrophic costal areas (Brylinsky 1981) where the risk of exposure to anoxia and sulphide is pronounced. The present study indicates that subitaneous A. tonsa eggs, which sink to the seabed and enter quiescence, can survive weeks to months in sediments but not years. The high tolerance to both anoxia and high sulphide concentrations shown by the eggs could favour their development in the estuaries, compared to those of less tolerant species; however, the population dynamics of $A$. tonsa may subsequently be affected.

\section{Implications for extrapolation of laboratory data}

Acartia tonsa reared in the laboratory over the past 25 years was the source of eggs tested in the present study. Therefore, one might be concerned when applying these results to natural populations in the field. An additional concern could be how Acartia tonsa eggs from different geographic areas might respond: are consistent results to be expected? Application of results from laboratory-reared organisms to field populations is always questionable. However, we do not consider that our results would differ significantly if experiments were conducted on eggs from a nearby field population or from eggs obtained from other geographical areas, because the present results were in accordance with other studies on eggs produced in the laboratory by organisms obtained from field populations (Marcus et al. 1997, Invidia et al. 2004).

\section{CONCLUSIONS}

The present study indicates that early stages of subitaneous eggs of Acartia tonsa can survive exposure to anoxia and sulphide for several weeks and months, but not for years. However, increased duration and sulphide concentrations during exposure reduces hatching success. An interesting question is how do eggs survive exposure to anoxia and sulphide? It has been stated that metabolic rate is drastically depressed when eggs are exposed to sulphide, owing to a switch to anaerobiosis (Marcus et al. 1997, Invidia et al. 2004). Invidia et al. (2004) also suggested that the eggshell was capable of blocking the entry of sulphide. But how is this possible when real-time studies (TAM results) demonstrated that eggs exposed to sulphide had a higher metabolism than eggs exposed to anoxia alone, and that eggs become decreasingly viable over time? The inevitable conclusion is that sulphide is capable of crossing the eggshell, and that the eggs have some kind of detoxification system. The costs of activating this detoxification system were responsible for the higher heat production (metabolism) observed when A. tonsa eggs were exposed to sulphide. According to simple calculations based on TAM results, A. tonsa eggs would require $37.6 \mathrm{~d}$ to metabolise the total amount of energy stored in the egg yolk when exposed to anoxia, but only $11.5 \mathrm{~d}$ if eggs were exposed to $14.7 \mathrm{mmol}^{-1}$ sulphide. In the long-term experiment, A. tonsa eggs exposed to anoxia were still capable of hatching after an incubation period of $240 \mathrm{~d}$, whereas eggs exposed to sulphide seemed to reach the limit of their tolerance level and could no longer hatch. The eggs survived for a disproportional long time when compared with calculated survival time, which suggests that $A$. tonsa eggs are equipped with an unknown defence mechanism against hydrogen sulphide.

Future studies of Acartia tonsa eggs, or copepod eggs in general, should concentrate on real-time observations where eggs are exposed to different sulphide concentrations in order to identify if they have a minimum tolerance level towards sulphide and a threshold exposure period. Measurements of actual internal sulphide concentrations of eggs, in addition to molecular biological studies, could also provide important insights into the mechanistic background and functioning of the suggested sulphide protection or detoxification system. These initiatives could help solve the mystery of how $A$. tonsa eggs cope with long term exposure to anoxia and sulphide.

Acknowledgements. Thanks are due to Danish Institute for Fishery Research Department of Ecology and Aquaculture for delivery of copepod egg inoculae. We also thank A. Faarborg, T. F. Sørensen and G. Drillet for technical assistance with copepod eggs, and Dr. P. Westh for help with the TAM. We are indebted to 4 unknown reviewers for their constructive comments on an earlier version of the manuscript. This project was supported by a Danish National Science Research Council grant (No. 21-01-0549) to B.W.H.

\section{LITERATURE CITED}

Alberts B (2002) Molecular biology of the cell. Taylor \& Francis, New York

Bagarinao T (1992) Sulfide as an environmental factor and toxicant: tolerance and adaptations in aquatic organisms. Aquat Toxicol 24:21-62

Berggreen U, Hansen B, Kiørboe T (1988) Food size spectra, ingestion and growth of the copepod Acartia tonsa during development; implication for determination of copepod production. Mar Biol 99:341-352

Brylinski JM (1981) Report on the presence of Acartia tonsa Dana (Copepoda) in the harbour of Dunkirk (France) and its geological distribution in Europe. J Plankton Res 3:255-260

Clegg JS (1997) Embryos of Artemia franciscana survive four years of continuous anoxia: the case for complete metabolic rate depression. J Exp Biol 200:467-475

Cline JD (1969) Spectrophotometric determination of hydrogen sulphide on natural waters. Limnol Oceanogr 14:454-458

Diaz RJ (2001) Overview of hypoxia around the world. J Environ Qual 30:275-281 
Drillet G (2003) Temperature and cold storage effects upon hatching success of subitaneous eggs from the calanoid copepod Acartia tonsa. MSc thesis, Roskilde University

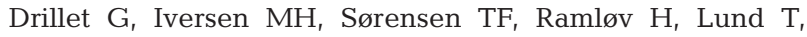
Hansen BW (2006) Effect of cold storage upon eggs of a calanoid copepod Acartia tonsa (Dana) and their offspring. Aquaculture 254:714-729

Fenchel T, Finlay BJ (1995) Ecology and evolution in anoxic worlds. Oxford University Press, Oxford

Fenchel T, Riedl RJ (1970) The sulfide system: a new biotic community underneath the oxidized layer of marine sand bottoms. Mar Biol 7:255-268

Grice GD, Marcus NH (1981) Dormant eggs of marine copepods. Oceanogr Mar Biol 19:125-140

Groenendaal M (1981) The adaptation of Arenicola marina to sulphide solutions. Meth J Sea Res 15:65-77

Hagerman L (1998) Physiological flexibility: a necessity for life in anoxic and sulphidic habitats. Hydrobiologia 375/376: 241-254

Hansen PJ (1989) The red tide dinoflagellate Alexandrium tamarense - effects on behaviour and growth on a tintinnid ciliate. Mar Ecol Prog Ser 53:105-116

Hansen PJ, Bjørnsen PK, Hansen BW (1997) Zooplankton grazing and growth: scaling within the $2-2000 \mu \mathrm{m}$ body size range. Limnol Oceanogr 42:687-704

Hinga KR (1992) Co-occurrence of dinoflagellate blooms and high $\mathrm{pH}$ in marine enclosures. Mar Ecol Prog Ser 86: 181-187

Hinga KR (2002) Effects of pH on coastal marine phytoplankton. Mar Ecol Prog Ser 238:281-300

Invidia M, Sei S, Gorbi G (2004) Survival of the copepod Acartia tonsa following egg exposure to near anoxia and to sulfide at different $\mathrm{pH}$ values. Mar Ecol Prog Ser 276:187-196

Kemp RB (1999) Handbook of thermal analysis and calorimetry. From macromolecules to man, Vol 4. Elsevier Science Publishers, New York

Lee RF, Hagen W, Kattner G (2006) Lipid storage in marine zooplankton. Mar Ecol Prog Ser 307:273-306

Lutz RV, Marcus NH, Chanton JP (1992) Effects of low oxygen concentrations on the hatching and viability of eggs of marine calanoid copepods. Mar Biol 114:241-247

Lutz RV, Marcus NH, Chanton JP (1994) Hatching and viability of copepod eggs at two stages of embryological development: anoxia/hypoxic effect. Mar Biol 119: 199-204

Marcus NH (1996) Ecological and evolutionary significance of resting eggs in marine copepods: past, present, and future studies. Hydrobiologia 320:141-152

Editorial responsibility: Otto Kinne (Editor-in-Chief), Oldendorf/Luhe, Germany
Marcus NH, Lutz RV (1994) Effects of anoxia on the viability of subitaneous eggs of planktonic copepods. Mar Biol 121: 83-87

Marcus NH, Lutz RV, Burrnett W, Cable P (1994) Age, viability, and vertical distribution of zooplankton resting eggs from an anoxic basin: evidence of an egg bank. Limnol Oceanogr 39:154-158

Marcus NH, Lutz RV, Chanton JP (1997) Impact of anoxia and sulfide on the viability of eggs of three planktonic copepods. Mar Ecol Prog Ser 146:291-295

Mauchline J (1998) Advances in marine biology, Vol 33. The biology of calanoid copepods. Elsevier Academic Press, Publishers, San Diego, CA

Nilsson HC, Rosenberg R (1994) Hypoxic response of two marine benthic communities. Mar Ecol Prog Ser 115: 209-217

Powell E (1989) Oxygen, sulfide and diffusion: why thiobiotic meiofauna must be sulfide-insensitive first-order respirers. J Mar Res 47:887-932

Roos A, Boron WF (1981) Intracellular pH. Physiol Rev 61: $296-434$

Sommer S, Jahn A, Funke F, Brenke N (2000) In vivo measurements of the internal $\mathrm{pH}$ of Hediste (Nereis) diversicolor (Annelida, Polychaeta) exposed to ambient sulphidic conditions using $\mathrm{pH}$ microelectrodes. Naturwissenschaften 87 : 283-287

Støttrup JG, Richardson K, Kirkegaard E, Pihl NJ (1986) The cultivation of Acartia tonsa Dana for use as a live food source for marine fish larvae. Aquaculture 52:87-96

Uye S, Fleminger A (1976) Effects of various environmental factors on egg development of several species of Acartia in southern California. Mar Biol 38:253-262

Vismann B (1990) Sulfide detoxification and tolerance in Nereis (Hediste) diversicolor and Nereis (Neanthes) virens (Annelida: Polychaeta). Mar Ecol Prog Ser 59:229-238

Vismann B (1996a) Sulfide species and total toxicity in the shrimp Crangon crangon. J Exp Mar Biol Ecol 204:141-154

Vismann B (1996b) Sulfide exposure experiments: the sulphide electrode and a set-up automatically controlling sulfide, oxygen and pH. J Exp Mar Biol Ecol 204:131-140

Vismann B, Hagerman L (1996) Recovery from hypoxia with and without sulfide in Saduria entomon: oxygen debt, reduced sulfur and anaerobic metabolites. Mar Ecol Prog Ser 143:131-139

Vopel K, Dehmlow J, Johansson M, Arlt G (1998) Effects of anoxia and sulphide on populations of Cletocamptus confluens (Copepoda, Harpacticoida). Mar Ecol Prog Ser 175: $121-128$

Submitted: February 27, 2006; Accepted: May 23, 2006

Proofs received from author(s): November 22, 2006 